\title{
Equatorial ionospheric zonal drift model and vertical drift statistics from UHF scintillation measurements in South America
}

\author{
R. E. Sheehan and C. E. Valladares \\ Institute for Scientific Research, Boston College, Chestnut Hill, Massachusetts, USA \\ Received: 17 December 2003 - Revised: 8 April 2004 - Accepted: 14 May 2004 - Published: 23 September 2004 \\ Part of Special Issue "Equatorial and low latitude aeronomy"
}

\begin{abstract}
UHF scintillation measurements of zonal ionospheric drifts have been conducted at Ancon, Peru since 1994 using antennas spaced in the magnetic east-west direction to cross-correlate geo-synchronous satellite signals. An empirical model of average drift over a wide range of $K_{p}$ and solar flux conditions was constructed from successive twodimensional fits of drift vs. the parameters and day of year. The model exhibits the typical local time trend of maximum eastward velocity in the early evening with a gradual decrease and reversal in the early morning hours. As expected, velocities at all hours increase with the solar flux and decrease with $K_{p}$ activity. It was also found that vertical drifts could contribute to the variability of drift measurements to the east of Ancon at a low elevation angle. The vertical drift at the ionospheric intersection to the east can be estimated when combined with nearly overhead observations at Ancon or a similar spaced-antenna site at Antofagasta, Chile. Comparisons on five days with nearly simultaneous measurements of vertical drift by the Julia radar at Jicamarca, Peru show varying agreement with the spaced-antenna estimates. Statistical results from 1997 to 2001 generally agree with radar and satellite studies.
\end{abstract}

Key words. Ionosphere (equatorial ionosphere; ionospheric irregularities; modeling and forecasting)

\section{Introduction}

A comprehensive understanding of the low latitude plasma electrodynamics is of great importance because of the controlling influence that plasma drifts and thermospheric winds exert on the number density distribution and on developing the favorable states conducive to the initiation of large-scale plasma bubbles. In general, the neutrals transfer momentum to the ions by collisions. In the F-region the ions move almost freely along the field lines; similarly, they create polariza-

Correspondence to: R. E. Sheehan

(sheehanp@bc.edu) tion electric fields that transport the plasma perpendicular to the B-field. During quiet magnetic conditions, the E- and Fregion neutral wind dynamos generate the equatorial electric fields (Rishbeth, 1970, 1981; Eccles, 1998). During magnetically disturbed periods, the penetration of E-field from high latitudes and the ionospheric disturbed dynamo can significantly modify the magnitude of the low latitude electric fields (Fejer and Scherliess, 1997).

At low latitudes the climatology of the zonal and vertical drifts has been defined based on measurements collected with incoherent scatter radars, satellites and scintillation receivers. Fejer et al. $(1981,1985)$ used measurements of drifts performed at Jicamarca to show that the zonal drift is westward and about $50 \mathrm{~m} / \mathrm{s}$ during the day, and eastward and up to $130 \mathrm{~m} / \mathrm{s}$ during the night. Coley and Heelis (1989) used drifts collected with the DE-2 satellite to show that these drifts coincided with the Jicamarca drifts. Their evening values of zonal eastward drifts peaking at $170 \mathrm{~m} / \mathrm{s}$ were typical for solar maximum conditions. They also observed drift reversals from westward to eastward at 19:00 LT and to westward drifts at 04:30 LT. Recently, Fejer and Scherliess (1998) were able to extract the temporal evolution of the low latitude penetration zonal drifts that is driven by the magnetospheric E-field. They observed the largest effect on the dusk to midnight sector with an average duration of $2 \mathrm{~h}$. Valladares et al. (1996) presented irregularity drifts observed during the first year of operations at Ancon. Their values were in agreement with the values measured at Jicamarca for solar minimum conditions.

More recently, Valladares et al. (2002) have compared the zonal drift measured with the scintillation technique at Ancon and the zonal wind measured by the FPI located at Arequipa. The drifts were close to the wind values; with the drifts exceeding the winds by $15 \mathrm{~m} / \mathrm{s}$ during the equinox and the opposite behavior was seen during the June solstice. They attributed the larger drift values to spatial variability of the zonal wind.

This paper presents statistical results of the zonal drifts measured using the spaced-antenna scintillation technique at 


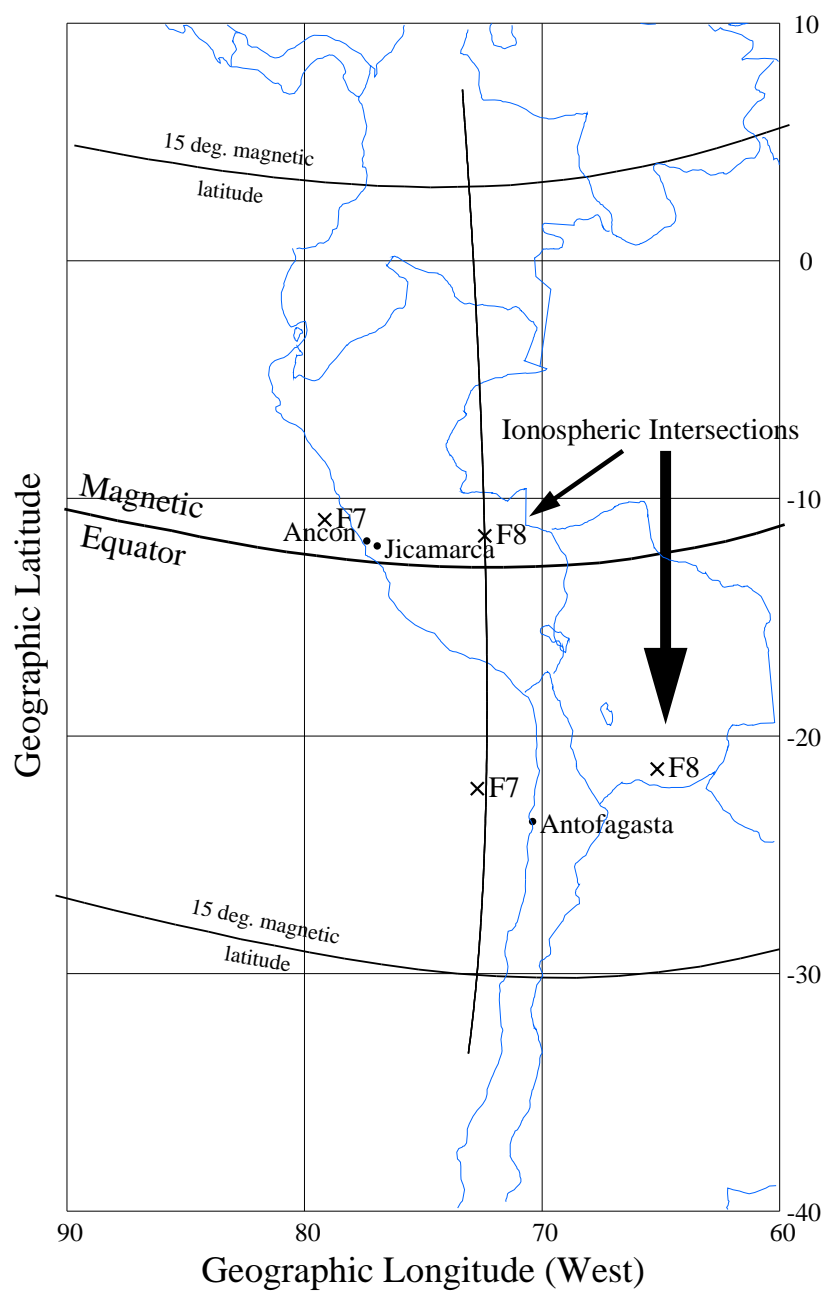

Fig. 1. Map of the west coast of South America showing the spacedreceiver sites at Ancon, Peru and Antofagasta, Chile, and the Julia radar at Jicamarca, Peru. F7 and F8 near Ancon indicate the 350-km ionospheric intersections of the Ancon-W and Ancon-E ray paths, respectively, to the F7 and F8 geostationary satellites. F7 and F8 near Antofagasta are the intersection points from Antofagasta to the same satellites.

two sites located near the west coast of South America. One of the sites, Ancon, Peru, is located near the magnetic equator, and the other is at Antofagasta, Chile $\left(11^{\circ} \mathrm{S}\right.$ magnetic latitude, $5^{\circ}$ east of Ancon). The study constitutes a continuing effort to develop an empirical model of the climatology and day-to-day variability of the zonal irregularity drift as a function of local time, season, magnetic, and solar conditions. It also seeks to represent the spatial and altitude/latitude dependency of the zonal drifts during the nighttime hours.

In a related effort, spaced receiver measurements at Ancon from a low-elevation satellite to the east were combined with Antofagasta drifts to give estimates of vertical drift velocities near Antofagasta. The vertical drift is an important factor in the instability leading to equatorial spread $\mathrm{F}$ and plasma bubbles (Fejer et al., 1999). Several case studies compare the results with data from the Julia radar at Jicamarca.

\section{Experimental setup}

The spaced receiver system at Ancon described in Valladares et al. (1996) cross-correlates UHF signal level data at $50 \mathrm{~Hz}$ from two geo-synchronous satellites, one nearly overhead located at $100^{\circ}$ west longitude (F7), the other low to the east at $23^{\circ}$ west longitude (F8). Figure 1 shows the locations of Ancon and a similar spaced antenna system at Antofagasta, Chile, along with the $350-\mathrm{km}$ ionospheric intersection points along the ray paths to the satellites. The intersection points F7 and F8 near Ancon will be designated Ancon-W, AnconE, respectively. Similarly, the points F7 and F8 near Antofagasta are the corresponding ionospheric intersections from Antofagasta. With the addition of Ancon-E in 1996, S4 and drift data have been collected nearly continuously up to the present.

Drift velocities at Ancon are calculated on-line using methods from Vacchione et al. (1987). This method uses quadratic approximations near the peaks of the cross- and autocorrelation functions to estimate both the drift velocity, $\mathrm{V}_{0}$, and the random velocity, $\mathrm{V}_{c}$, which is related to the amount of decorrelation over the sample time interval. When $\mathrm{V}_{c}=0$ (maximum cross-correlation=1), $\mathrm{V}_{0}$ is identical to the apparent drift velocity calculated from the lag of the maximum cross-correlation. $\mathrm{V}_{0}$ decreases relative to the apparent velocity as $\mathrm{V}_{c}$ increases (maximum cross-correlation decreases).

\section{Statistical results}

Drift velocities measured at Ancon-W from 1994 to 2001 were sorted into solar flux bins and plotted against mean local time (LT=UT-5h). Figure 2 summarizes the results for each season. Except for the June solstice when there were fewer points, there is a broad pre-midnight peak in eastward drift, followed by a slight post-midnight increase, or leveling off, and then a reversal to westward drift. Average drift velocities at all local times generally increase with solar flux, with the time of reversal occurring near local sunrise. The most pronounced post-midnight peak occurs during the March equinox, while during the December solstice the decline in eastward drift pauses before decreasing again and quickly reverses at about 05:00 local time. Similar trends are seen in Fig. 3 for Ancon-E drift data, although, as proposed in Sect. 5, vertical drifts contribute to the calculated drift because of the oblique ray path, and, since vertical drifts are predominantly downward after local sunset, the observed drifts appear consistently larger. The average drifts at Antofagasta (Fig. 4) are less consistent, and the pre-midnight peak tends to be somewhat earlier than at Ancon. The earlier peak is probably attributable to Antofagasta's location near the eastern border of the local time zone. These results were further broken into two broad categories of $D_{s t}$ index to separate the effect of magnetic storms. During active conditions $\left(D_{s t}<-23\right)$ at Ancon-W (Fig. 5a), the zonal drifts are generally $10-20 \mathrm{~m} / \mathrm{s}$ slower in all seasons and solar flux levels, 
compared to quiet conditions (Fig. 5b). The post-midnight enhancement, or leveling off, is seen in all seasons and conditions, but is most noticeable with active conditions during the vernal equinox.

To separate the influences of geomagnetic and solar conditions on the statistical distribution of zonal drifts, a twostep procedure was performed on the Ancon-W data from 1994 to 2002. Drifts were sorted into 12 local time bins, and a two-dimensional, second-order fit of the drift vs. $K_{p}$ and the day of year was calculated in each bin. The drift data in each local time bin were then referenced to the model drift at a fixed $K_{p}$ by subtracting the difference between the fit value of the drift and the fit value at $K_{p}=2$; $\mathrm{V}_{\text {Oref }}=\mathrm{V}_{0}-\left(\mathrm{V}_{0 \text { fit }}\left(K_{p}\right)-\mathrm{V}_{0 \text { fit }}\left(K_{p}=2\right)\right)$, where $\mathrm{V}_{0}$ is the measured drift and $\mathrm{V}_{0 \text { fit }}\left(K_{p}\right)$ is the fit value of drift. This in effect attributes the remaining dependence to the solar flux and other unspecified variables. A second two-dimensional fit was then carried out for $\mathrm{V}_{\text {0ref }}$ vs. solar flux and the day of year. A model drift for a given solar flux, $K_{p}$ and day of year can be found by reversing the steps using a set of coefficients describing the two-dimensional fits. The Appendix gives the coefficients and a more detailed description.

Figures 6a-d illustrate the dependence of the empirical model zonal drift on $K_{p}$ and the solar flux for each month. The $K_{p}$ dependencies are shown for two extreme levels of solar flux, and also the solar flux dependencies for quiet and active levels of $K_{p}$ activity. The drift dependencies are similar for all months, decreasing vs. $K_{p}$ and increasing vs. solar flux. These, in turn, are superimposed on the dependence on the other parameter, as seen when comparing Figs. 6a and b, and Figs. $6 \mathrm{c}$ and d. Further refinements to the model are possible, but its main purpose is to provide a compact summary of zonal drifts at Ancon over a wide range of geophysical conditions.

\section{Vertical drift}

Drift velocities calculated from UHF scintillations along the low-elevation path to the east of Ancon are often larger and have more scatter than those from nearly overhead. Kil et al. (2000) noted that for ray paths at low elevation angles, vertical drifts contribute to the cross-correlation used for zonal drift calculations. Another effect is an overestimate of the zonal drift at low elevation angles caused by the Earth's curvature. Figure 7 depicts the geometry at Ancon, where vectors at $350-\mathrm{km}$ altitude represent drifting irregularities directly overhead and at a $28^{\circ}$ elevation angle to the east. The earth's curvature in this diagram is to scale, but the drift vectors have been exaggerated for clarity; the local horizontal and vertical components of the drift velocity are assumed to be the same at each location. An additional assumption is that scattering is only weak to moderate, so that an irregularity casts a shadow-like interference pattern on the ground along the continuation of the ray path from the satellite through the irregularity (dotted lines). As seen in the figure, the "shadow" looking to the east travels farther in a unit time than the one overhead, leading to a larger calculated drift velocity, $\mathrm{V}_{0}$. For purely horizontal drifts, the angular difference in local verticals due to the Earth's curvature causes an apparent downward vertical drift, as seen from Ancon looking toward the east. At an elevation angle of $28^{\circ}$ and $350-\mathrm{km}$ intersection altitude (ground distance $\sim 570 \mathrm{~km}$ ) the difference in local verticals is $\sim 5^{\circ}$. Therefore, for zonal drifts, velocity measurements to the east should be multiplied by a correction factor of .86 .

The vertical drift at the east intersection point can be determined from the measured $\mathrm{V}_{0}$ and an independent measurement of the horizontal drift. Figure 8 depicts the geometry at the east intersection point. The angle $\theta$ is the difference between the local horizontals at Ancon and the east intersection point; $\varepsilon$ is the elevation angle of the intersection point. The velocity perpendicular to the line of sight is the sum of the $\mathrm{V}_{h}$ and $\mathrm{V}_{v}$ components in that direction; $\mathrm{V}_{0} \sin (\varepsilon)=\mathrm{V}_{h}$ $\cos (\gamma)+\mathrm{V}_{v} \sin (\gamma)$, where $\gamma=(90-\varepsilon-\theta)$ and $\mathrm{V}_{0}$ is the measured drift at Ancon. The vertical drift $\mathrm{V}_{v}$ can then be determined from $\mathrm{V}_{0}$ and $\mathrm{V}_{h}$.

Because the Ancon-E (F8) and Antofagasta (F7) 350-km ionospheric intersection points are almost at the same magnetic longitude (Fig. 1), Antofagasta can provide the horizontal drift values needed to compute vertical drifts from Ancon $\mathrm{V}_{0}$ measurements. Figures $9 \mathrm{a}-\mathrm{e}$ are examples of vertical drifts calculated from Antofagasta and Ancon scintillations on 7 and 9 March and 3-5 April 1997. The top panels show horizontal drift velocities at Antofagasta and Ancon looking east; the bottom panels show calculated vertical drifts and Julia radar vertical drift velocities averaged over a $340-360 \mathrm{~km}$ altitude range in one-minute intervals, similar to the duration of scintillation samples. The Julia radar, located at Jicamarca near Ancon, detects drifting 3-m irregularities. Julia velocity points have been shifted $1.5 \mathrm{~h}$, the time to travel the distance between the Julia and Antofagasta longitudes at a nominal $100 \mathrm{~m} / \mathrm{s}$ zonal drift velocity. On 7 and 9 March the agreement between the scintillation and Julia velocities is poor, while on 3-5 April there is better agreement over extended periods. Given the uncertainty that the pattern of vertical drifts persists until it reaches the Antofagasta longitude, case by case agreement cannot be expected, especially during the dynamic growth phase of a plume. Also, because the Antofagasta intersection point maps to about $500 \mathrm{~km}$ apex altitude at the magnetic equator, height variations in horizontal drift are neglected (Pingree and Fejer, 1987; Basu et al., 1996). An alternative procedure is to use Ancon overhead $V_{0}$ to specify the horizontal drift. In this case the intersection points are at the same altitude over the magnetic equator but separated in longitude by $5^{\circ}$ and 1 to $2 \mathrm{~h}$ in time.

Although individual case studies, like those in Fig. 9, show some agreement with radar measurements in the vicinity, statistical results over several years would lend more credibility if they exhibited trends seen in other studies. The panel for each year in Fig. 10a shows average vertical drift velocities, computed from Antofagasta and Ancon-E data, in one-hour bins, from 00:00 to 08:00 UT, during the months of February to April, when scintillation activity is common in South 

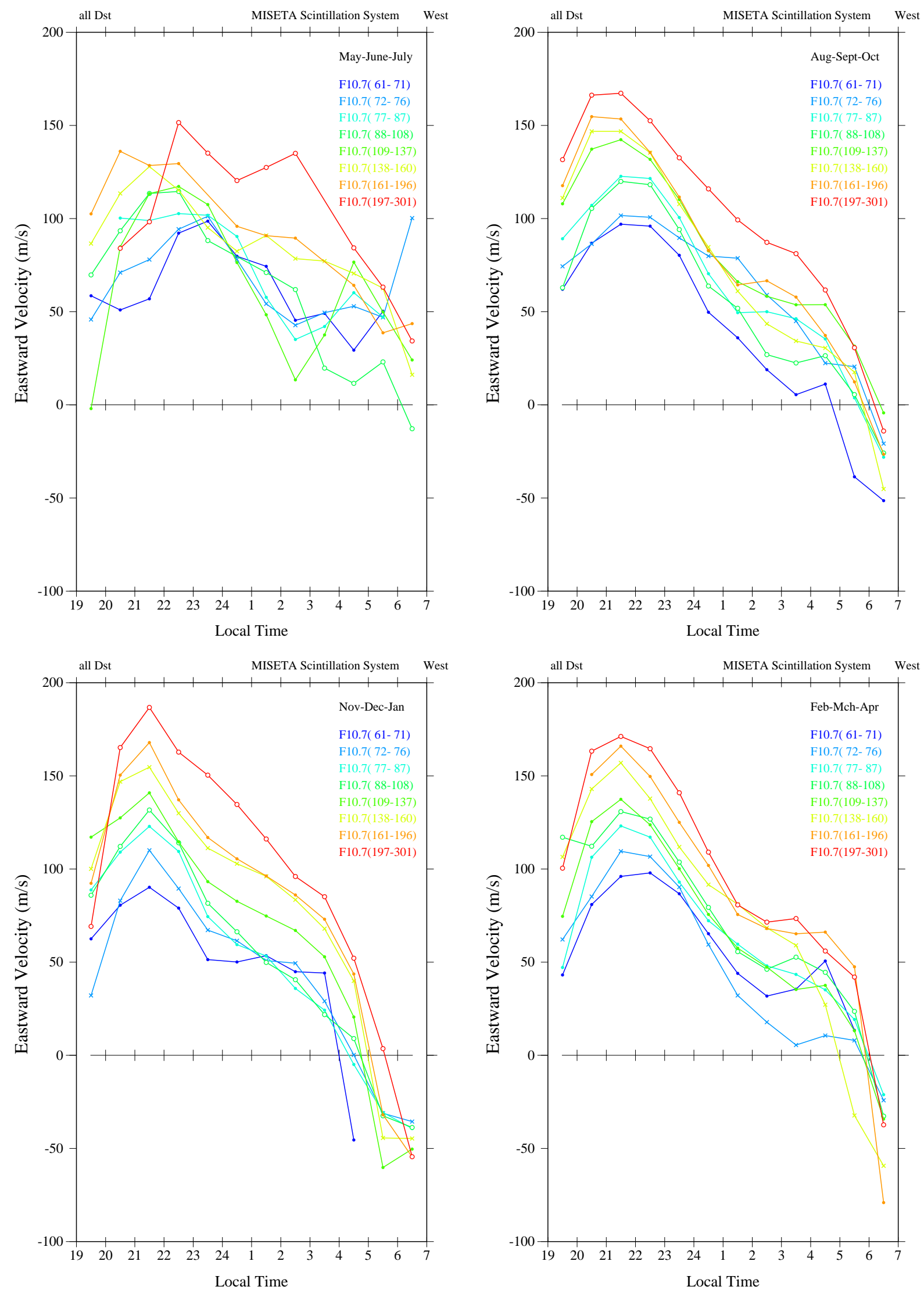

Fig. 2. Seasonal average zonal drifts for Ancon-W vs. local time (LT=UT-5h) binned into 8 levels of solar flux activity. 

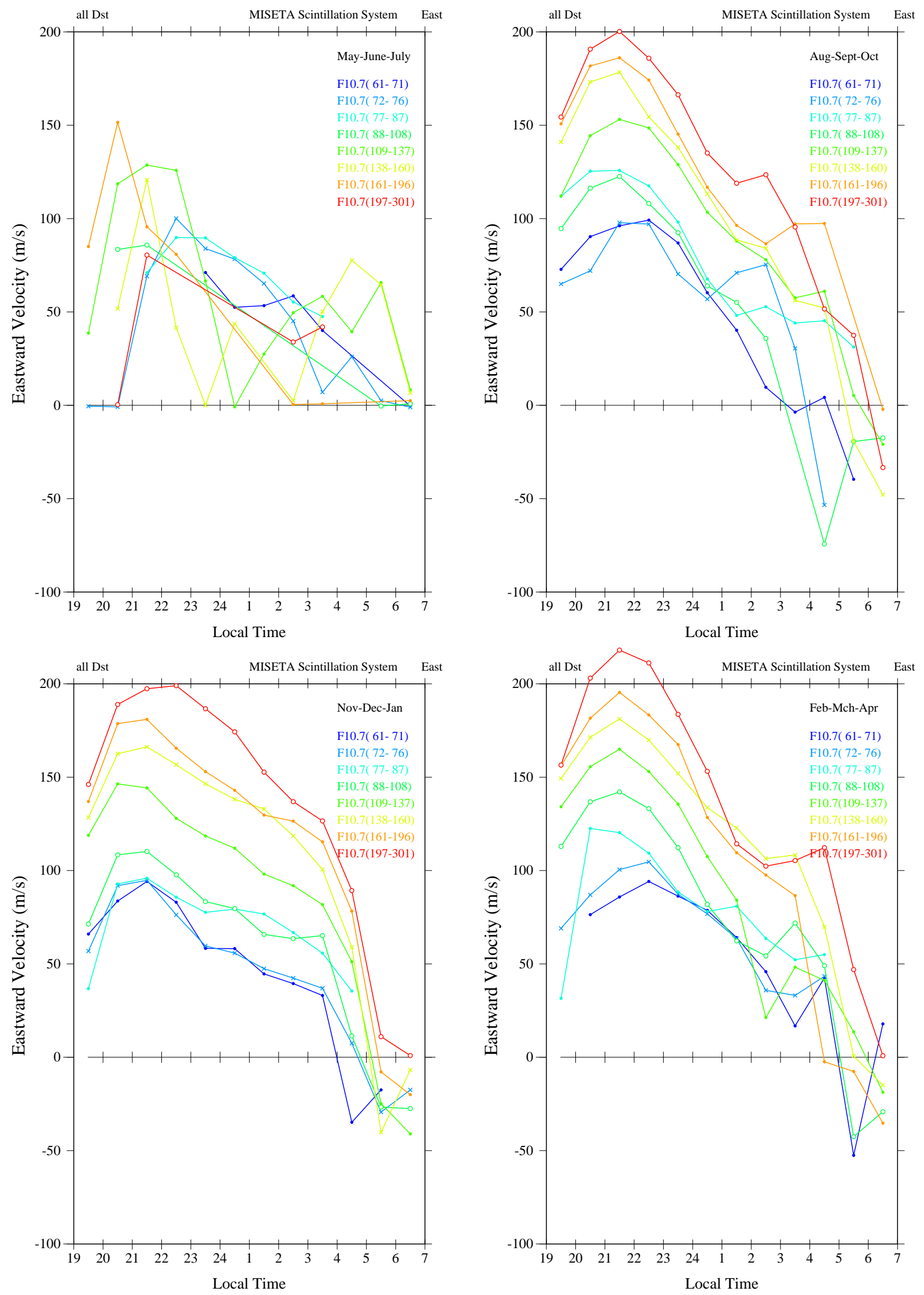

Fig. 3. Seasonal average zonal drifts for Ancon-E. 

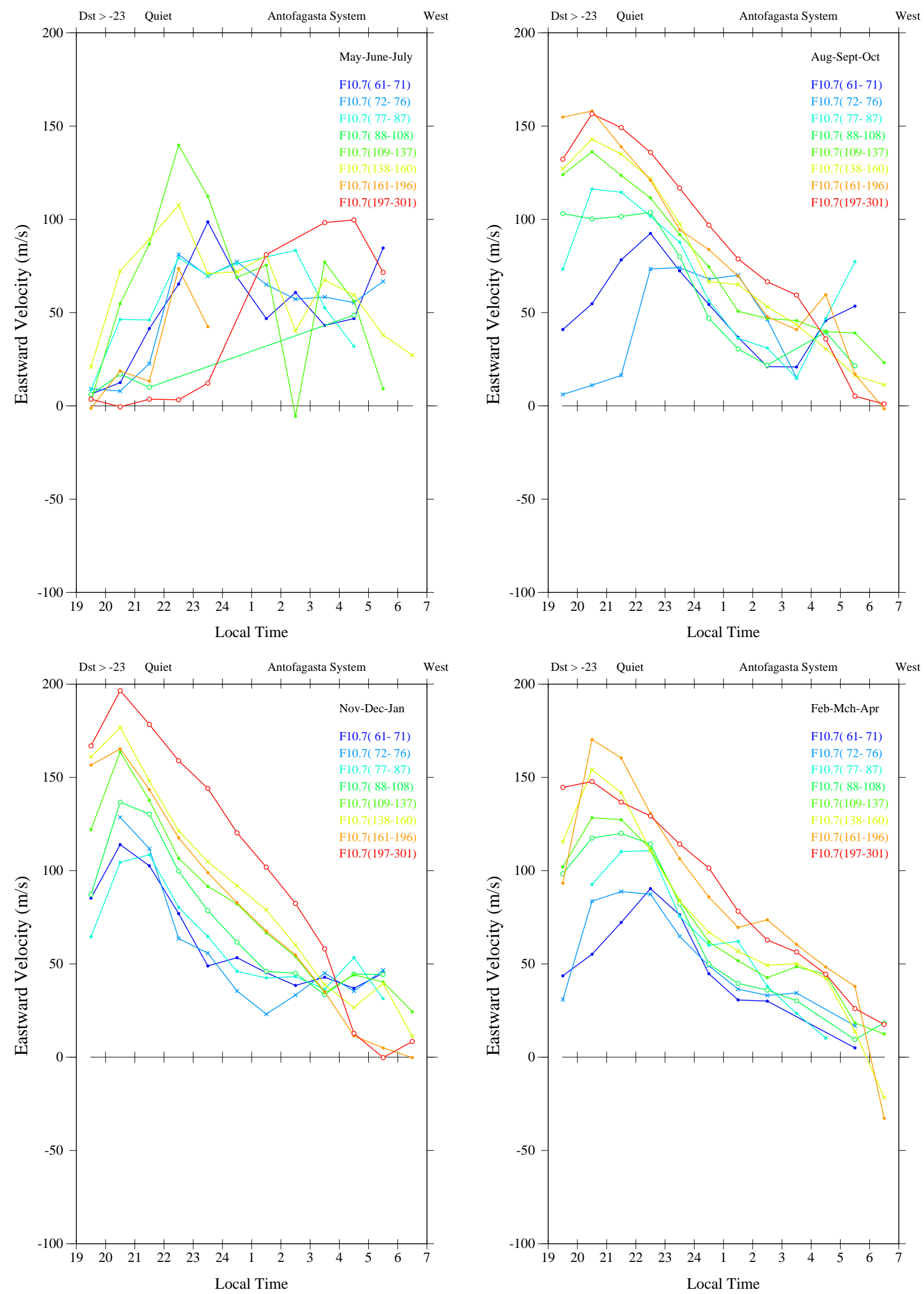

Fig. 4. Seasonal average zonal drifts for Antofagasta. 

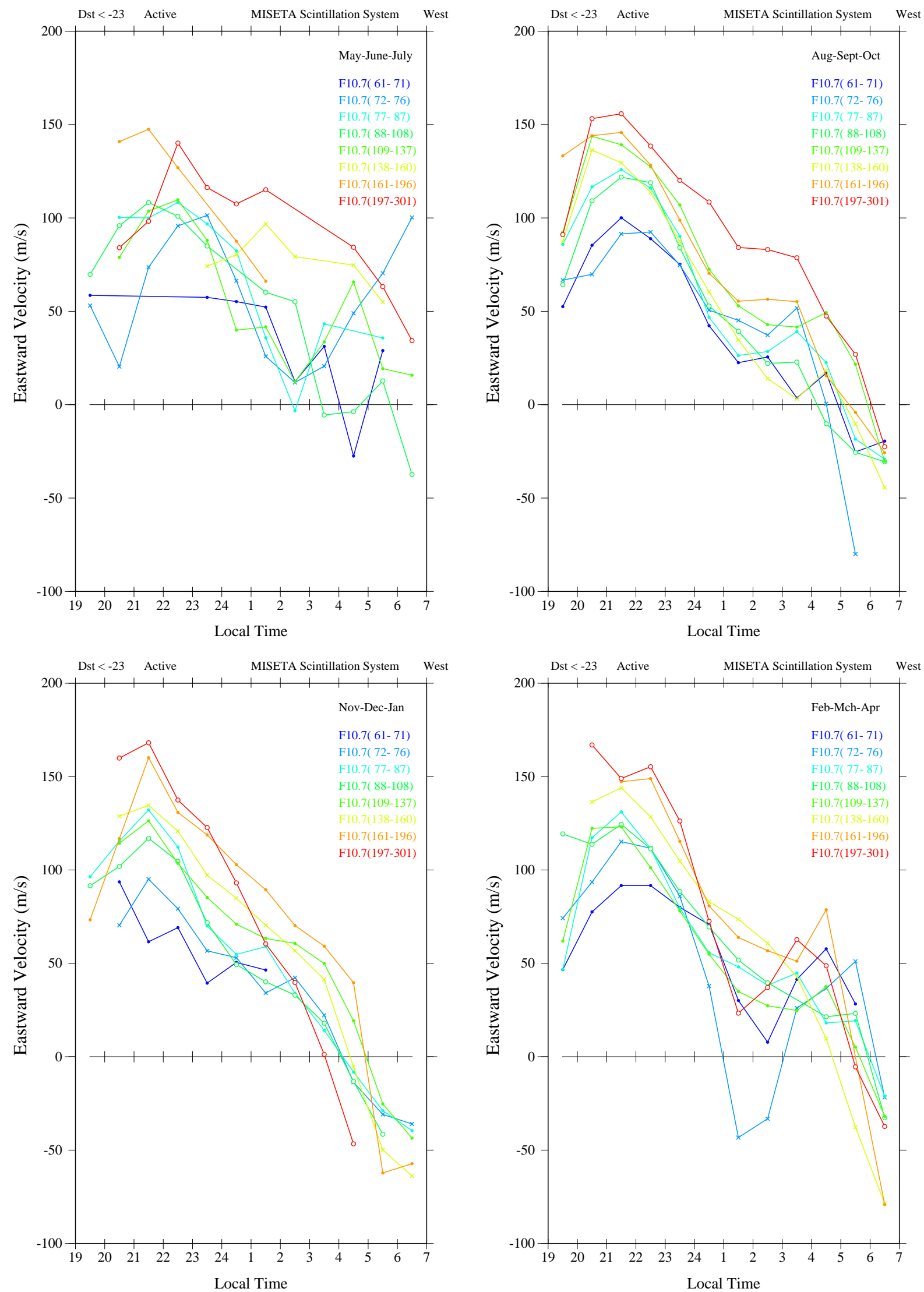

Fig. 5. (a) Seasonal average zonal drifts for Ancon-W, active $D_{s t}(<-23)$. 

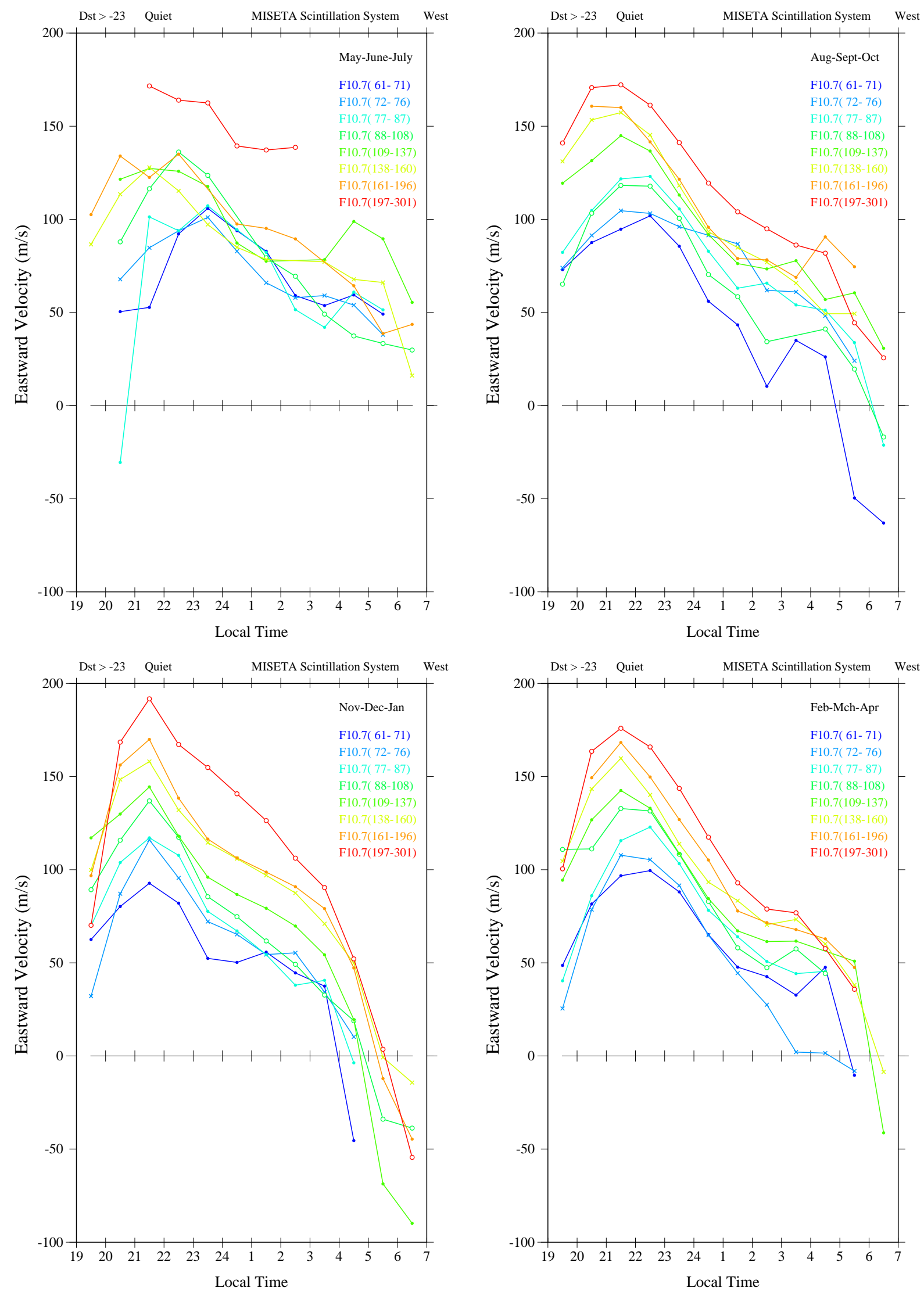

Fig. 5. (b) Seasonal average zonal drifts for Ancon-W, quiet $D_{s t}(>-23)$. 
Zonal Velocity Dependence Kp Dependency
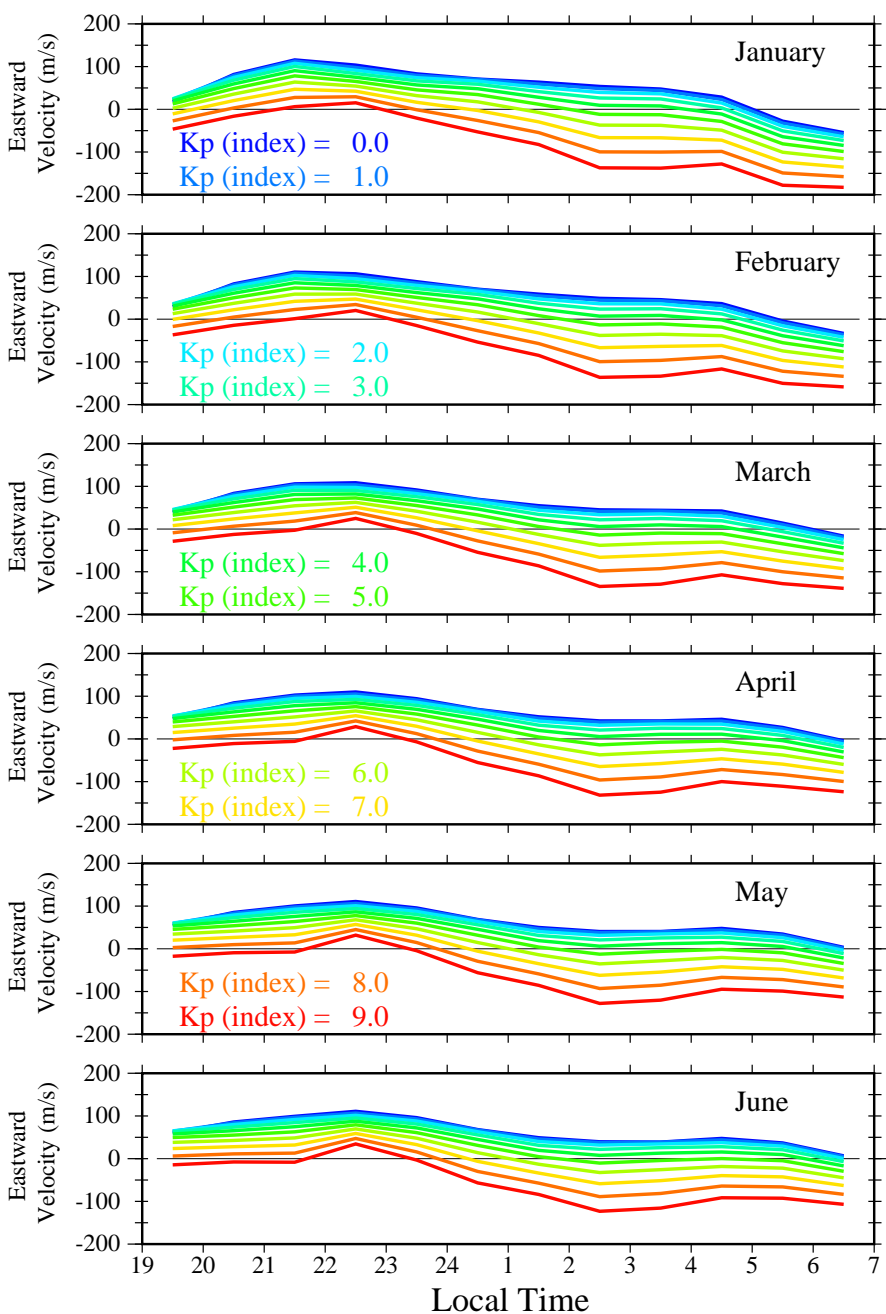

Solar Flux $=70.0 \quad$ Ancon site west
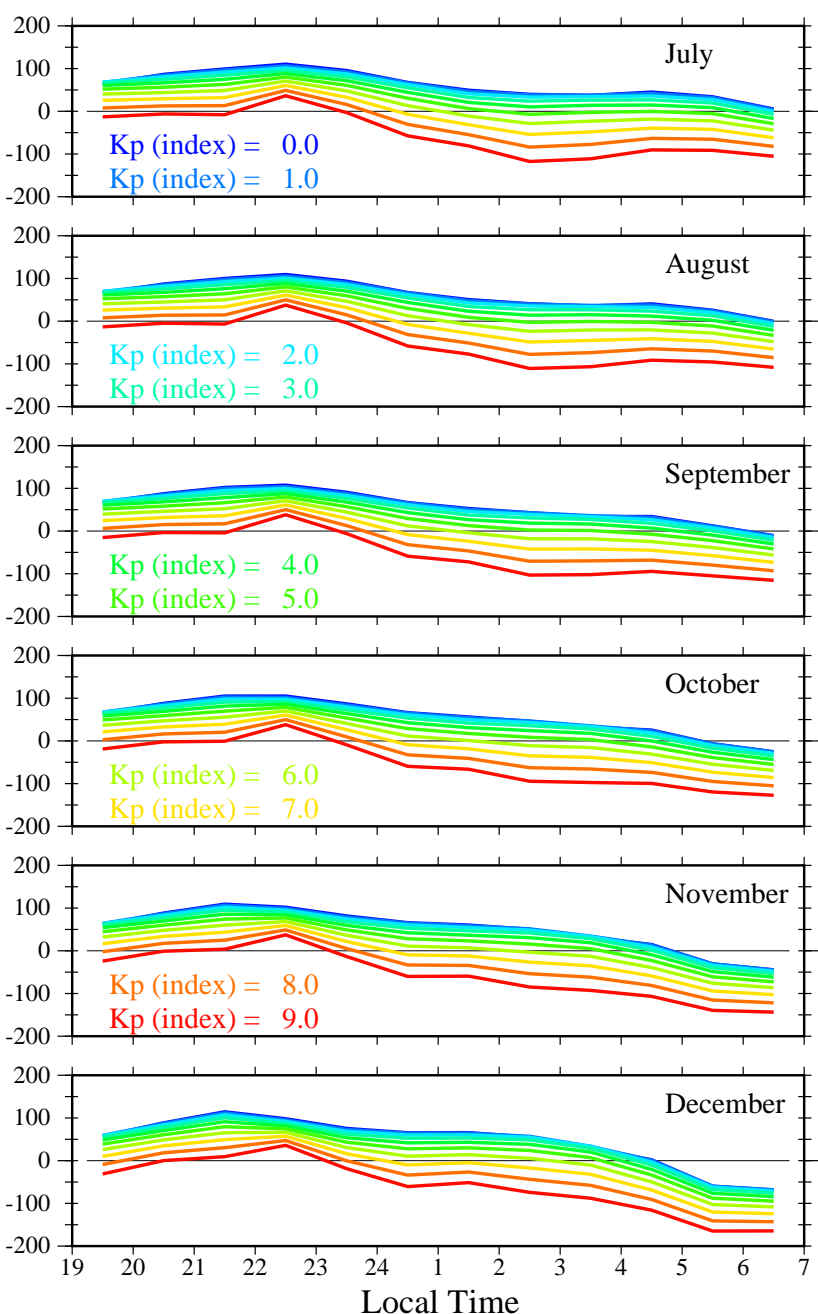

Fig. 6. (a) Ancon zonal drift dependence on $K_{p}$, solar flux=70. 

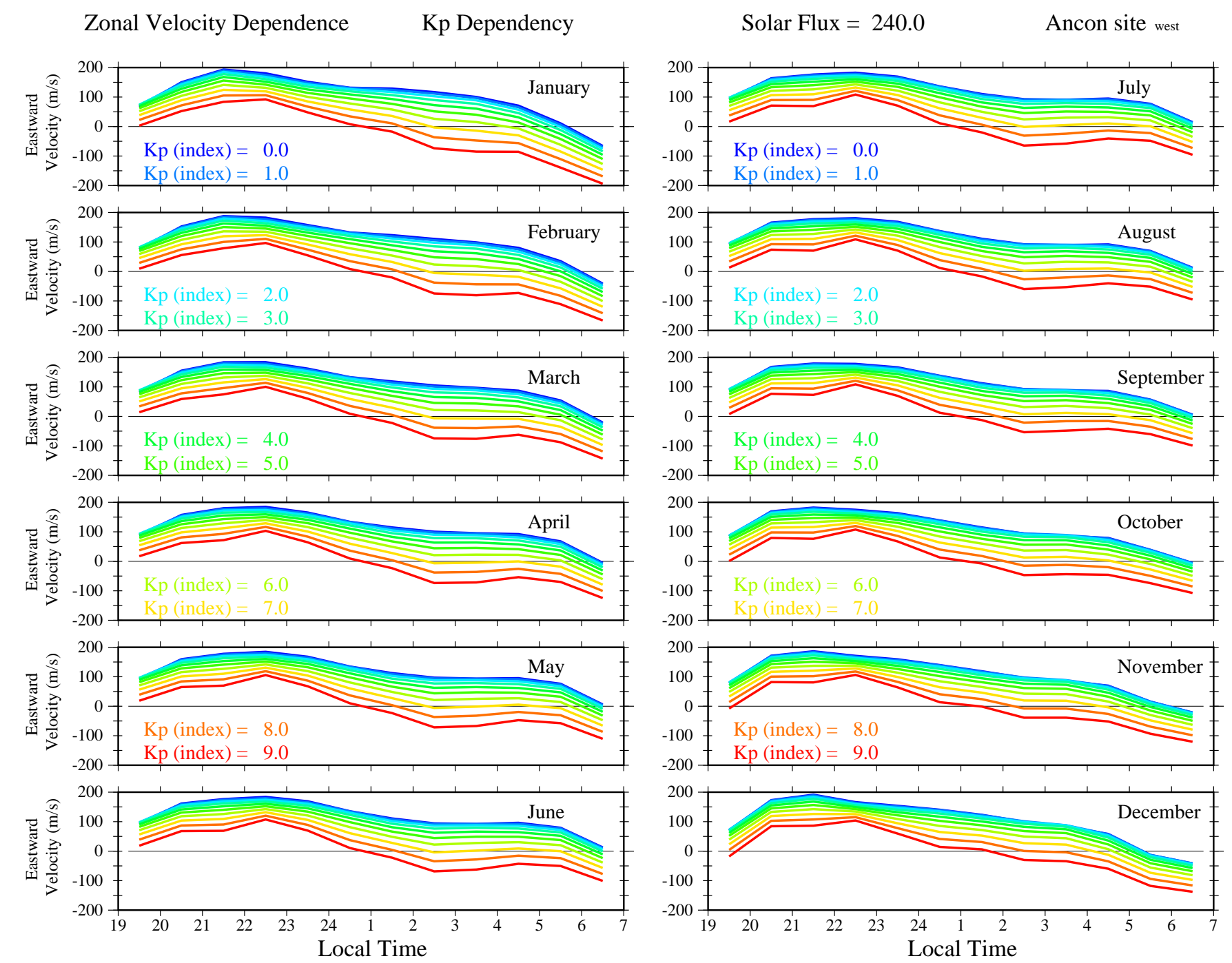

Fig. 6. (b) Ancon zonal drift dependence on $K_{p}$, solar flux=240. 


\section{Zonal Velocity Dependence Solar Flux Dependency}
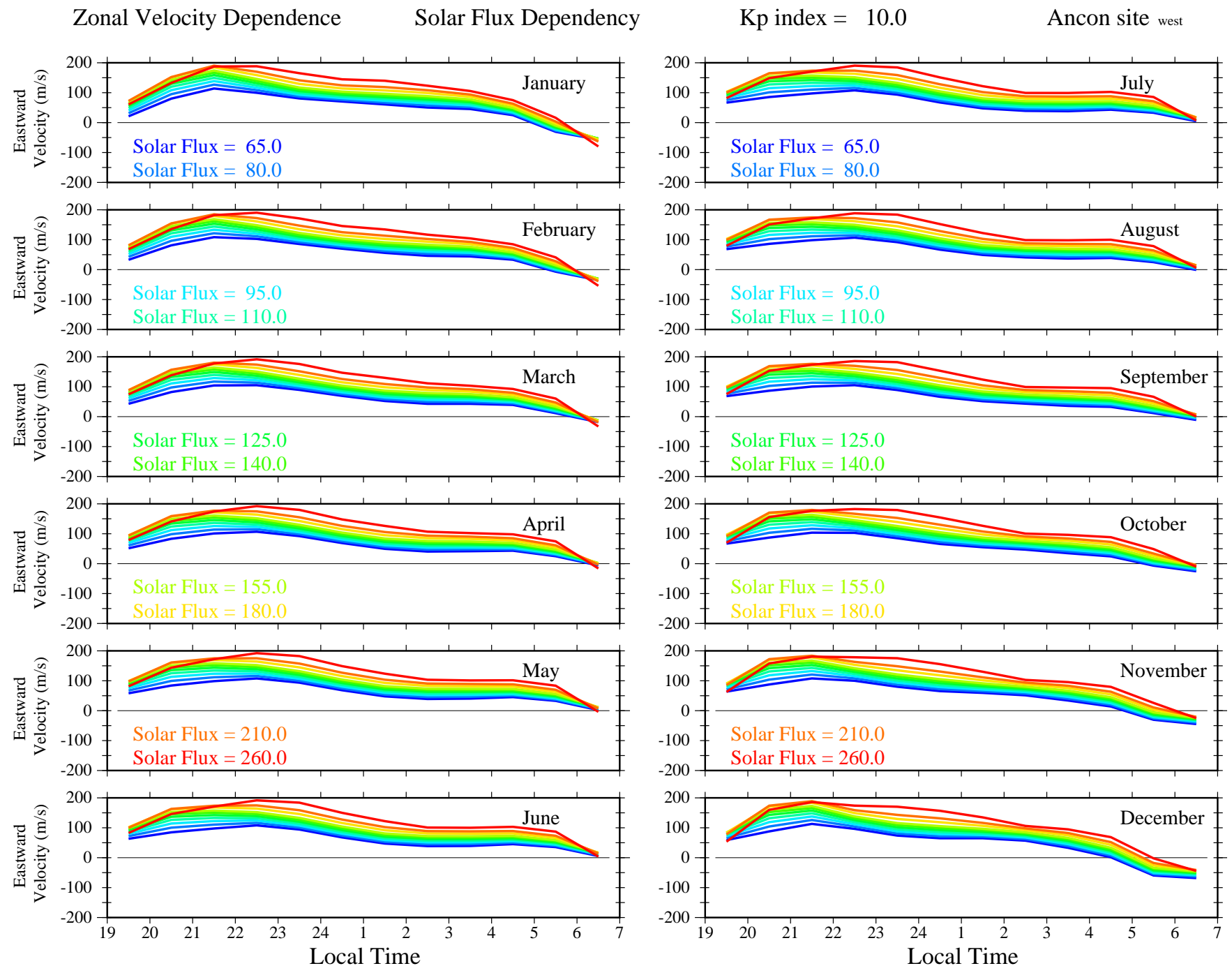

Fig. 6. (c) Ancon zonal drift dependence on solar flux, $K_{p}=1$. 


\section{Zonal Velocity Dependence Solar Flux Dependency}
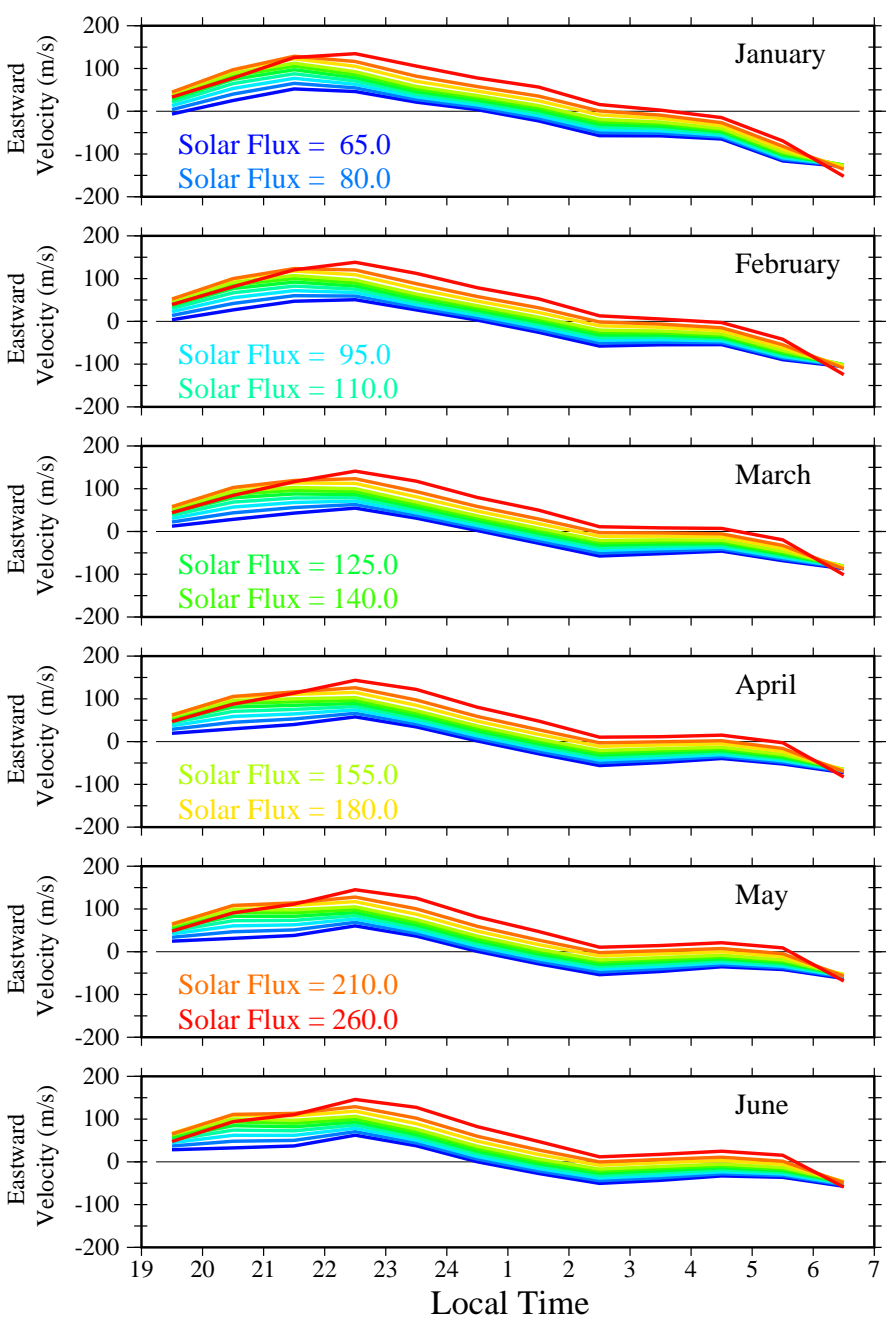

Kp index $=70.0$

Ancon site west
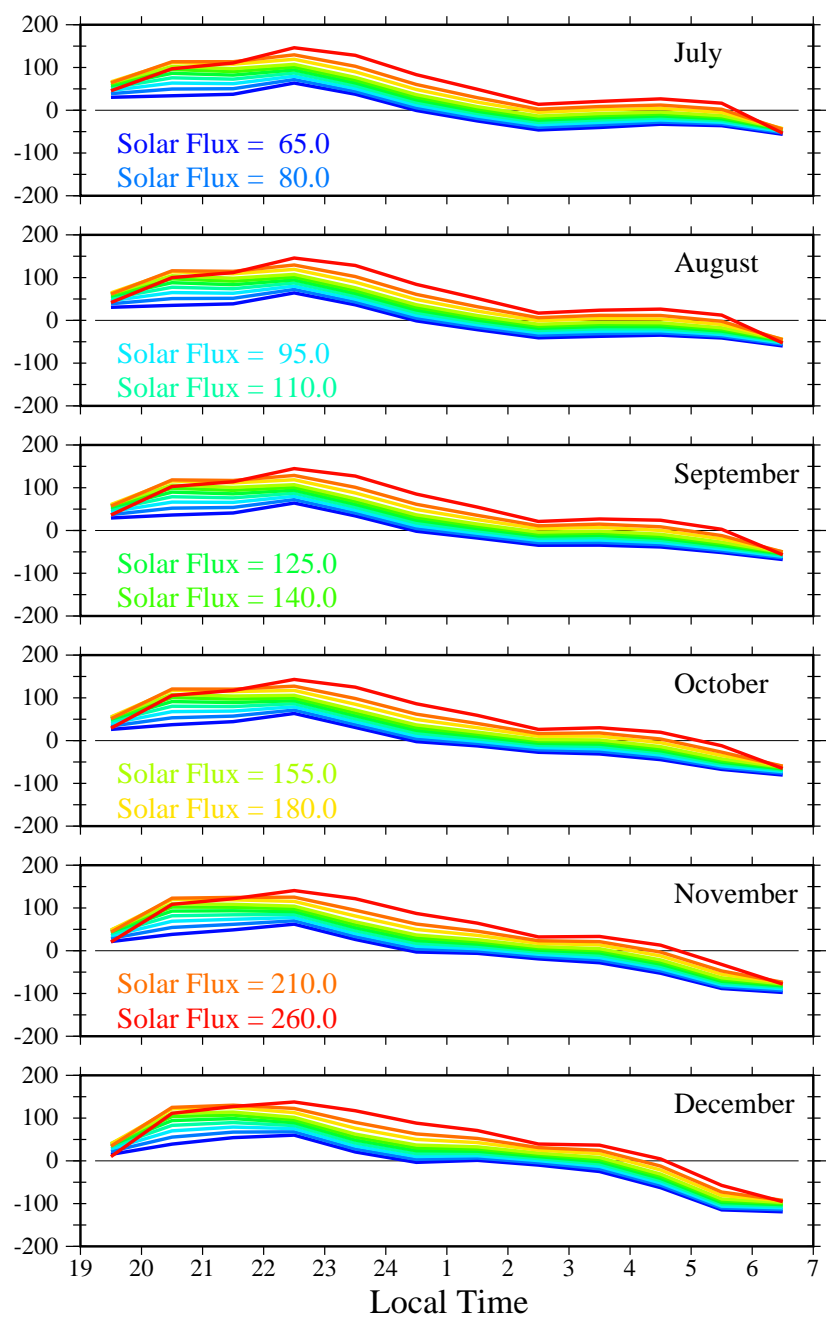

Fig. 6. (d) Ancon zonal drift dependence on solar flux, $K_{p}=7$. 


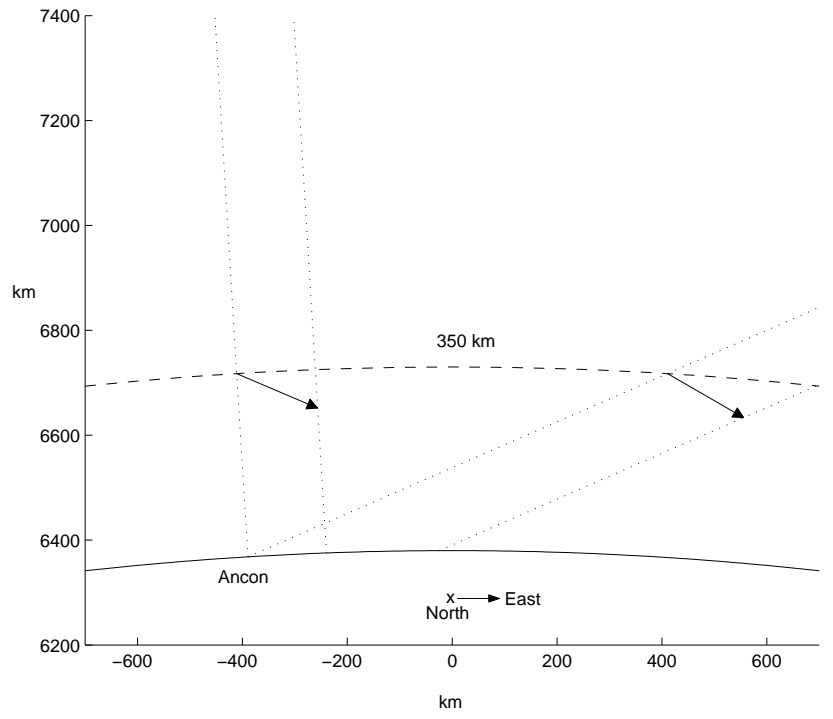

Fig. 7. View geometry from Ancon (approximately to scale). Dotted lines indicate ray paths intersected by drifting irregularities viewed nearly overhead and low to the east.

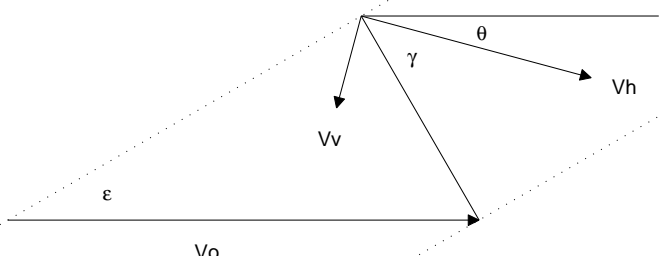

Fig. 8. Geometry at the Ancon-E ionospheric intersection point. Irregularities with horizontal and vertical drift components $\mathrm{V}_{h}$ and $\mathrm{V}_{v}$, respectively, yield a calculated $\mathrm{V}_{0}$ at Ancon-E.
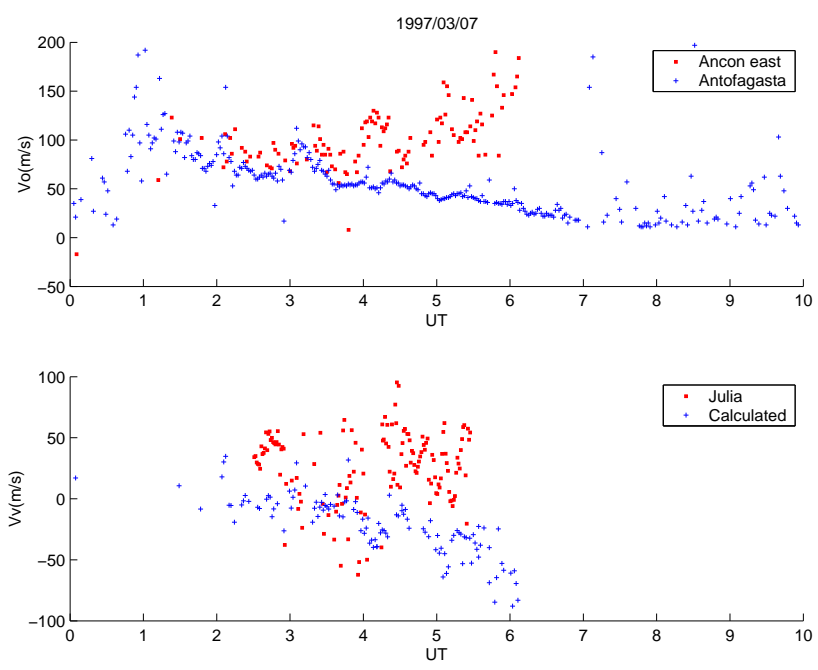

Fig. 9. (a) Top panel: Observed $V_{0}$ drift velocities at Ancon-E and Antofagasta on 7 March 1997. Bottom panel: Observed Julia radar vertical drifts and vertical drifts calculated from Ancon-E and Antofagasta $\mathrm{V}_{0}$ in top panel. Julia data is displaced $1.5 \mathrm{~h}$ later to account for zonal drift.
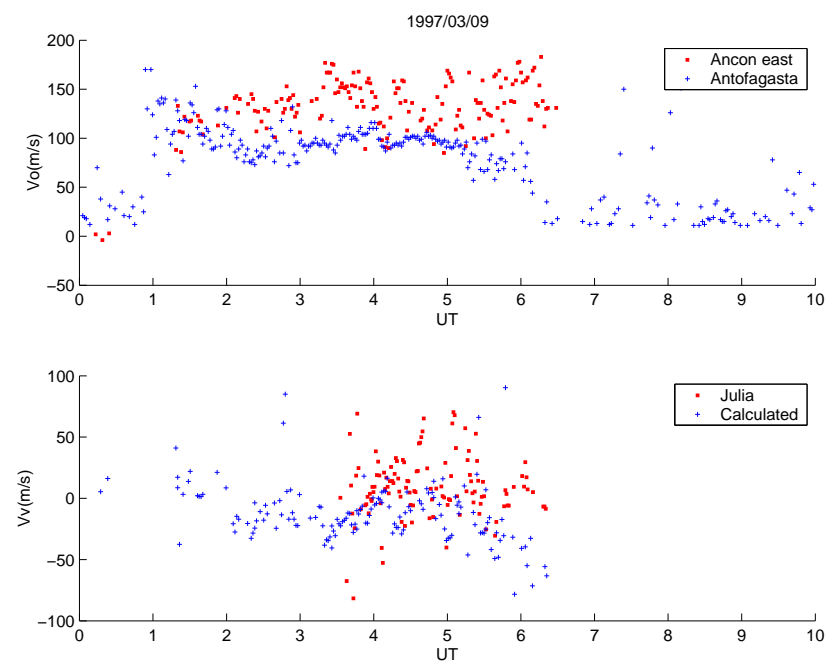

Fig. 9. (b) Same as Fig. 9a for 9 March 1997. 

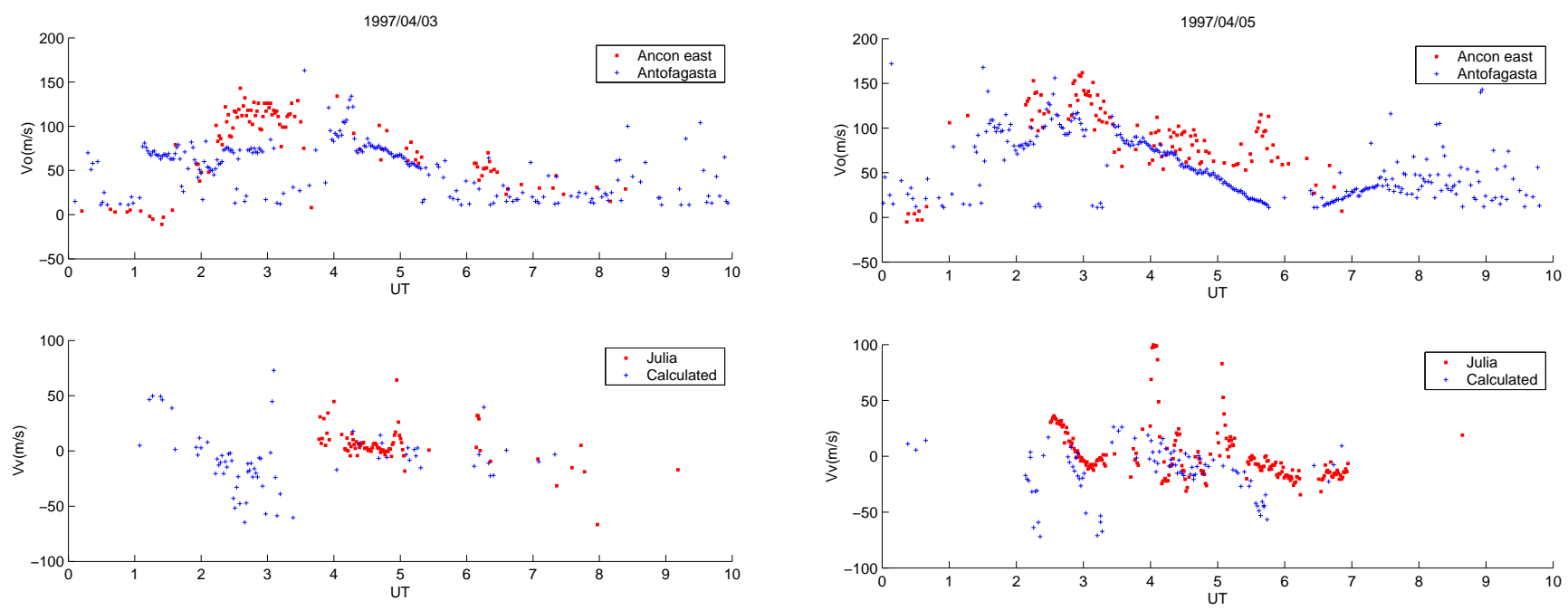

Fig. 9. (c) Same as Fig. 9a for 3 April 1997.

Fig. 9. (e) Same as Fig. 9a for 5 April 1997.
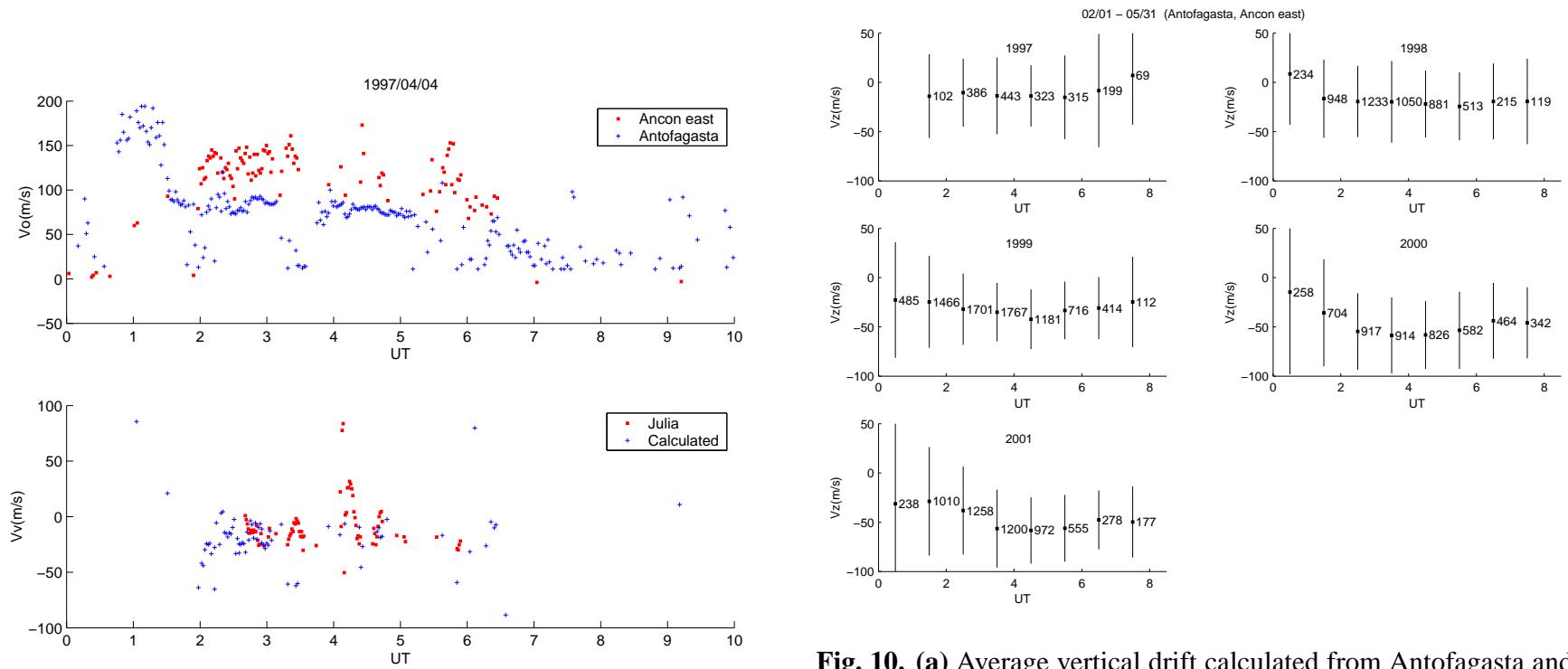

Fig. 10. (a) Average vertical drift calculated from Antofagasta and Ancon-E $\mathrm{V}_{0}$ data vs. UT for the months February-May from 1997 to 2001 .

Fig. 9. (d) Same as Fig. 9a for 4 April 1997. 

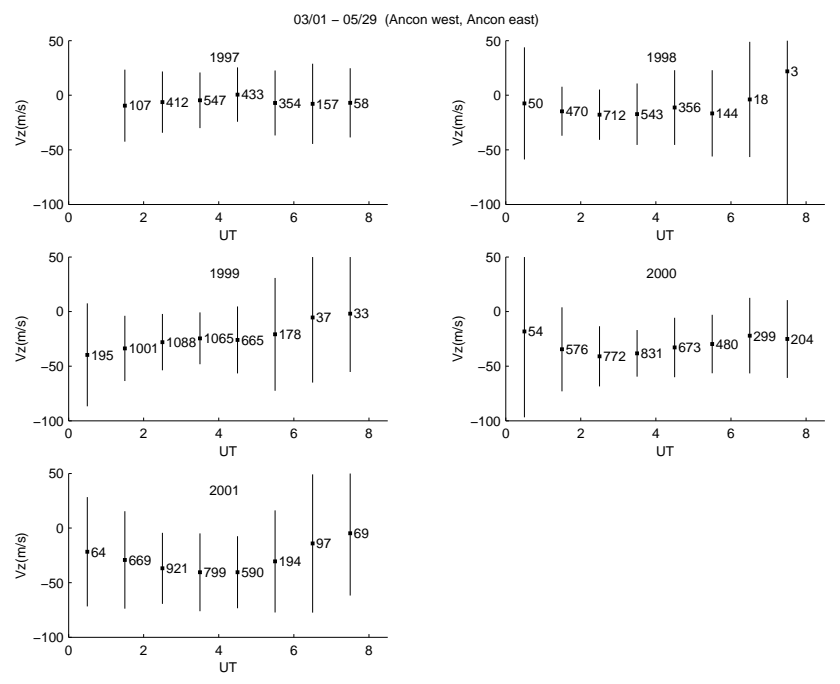

Fig. 10. (b) Same as Fig. 10a except data is from Ancon-W instead of Antofagasta.

America, and also including cases occurring in May. These results can be compared with equinox statistics from Fig. 1 in Fejer et al. (1991), which shows Jicamarca velocities that are generally negative (downward) from 20:00 to 03:00 LT (01:00 to 08:00 UT in Fig. 10a). In Fig. 10b Ancon-W supplies the horizontal velocity; the results are similar except that vertical drifts are somewhat less negative in 2000-2001. Since Ancon-E data is common to both figures, differences result from the horizontal drift data source, each of which suffers from its own drawback mentioned above. The Jicamarca data range from about -20 to $-60 \mathrm{~m} / \mathrm{s}$ for solar fluxes ranging from less than 100 to greater than 150 , indicating that the more negative drifts in Figs. 10a and b around the year 2000 are consistent with increased solar activity. Valladares et al. (1996) found systematic differences between zonal drifts measured by incoherent radar and scintillation techniques which may apply to the vertical drifts as well. The vertical drift statistics include all geomagnetic and solar conditions and have rather large error bars that make the UT trend in each year suggestive but not definite.

\section{Conclusions and discussion}

The zonal drift statistics presented here update the first results of Valladares et al. (1996) through the current solar maximum. As noted by Fejer et al. (1985), eastward zonal drift velocities measured by the Jicamarca incoherent radar are generally slower than those seen by two spaced receivers. Figure 11 shows a linear fit of all the Ancon spacedreceiver zonal drift data (1994-2002) vs. solar flux during the equinoxes at 02:00 LT, generally the time of maximum eastward velocity. Each solar flux bin of 10 units has 1000 or more points up to flux $=205$ and over 200 points up to flux $=245$. A similar plot of the Jicamarca eastward peak velocity (Fig. 8 in Fejer et al., 1991) has comparable error bars,

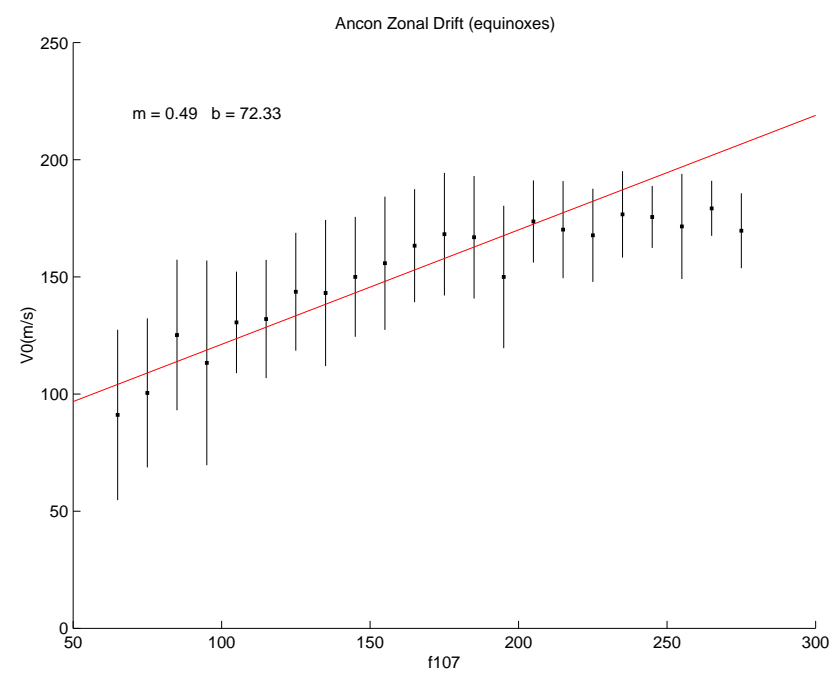

Fig. 11. Linear fit to Ancon zonal drift measurements in 02:00 LT bin vs. solar flux during the equinoxes (all data 1994-2002).

a slope of 0.45 and an intercept at $60.01 \mathrm{~m} / \mathrm{s}$. The higher intercept and slightly steeper slope in Fig. 11 confirm that average spaced-receiver drifts are about $10-20 \mathrm{~m} / \mathrm{s}$ faster than the average Jicamarca drifts. In Fig. 11 the average drift stops increasing and remains at approximately $150 \mathrm{~m} / \mathrm{s}$ when the solar flux exceeds 200, which indicates that the second-order fit in the empirical model presented here is a better approximation than a linear fit. However, the relatively large error bars for the solar flux and the $K_{p}$ dependences mean that a broad range of drift velocities are associated with these global indices and the details depend more on local dynamic conditions.

After the installation of the Ancon-E antennas, it was noted that the measured drift velocities to the east were usually greater and more variable than the zonal drifts seen by Ancon-W nearly overhead. It was realized that, in addition to the longer path through the ionosphere, the viewing geometry could introduce contributions from real vertical drifts and an apparent vertical drift due to the Earth's curvature. This conclusion assumes mostly forward scatter of radio waves by $\mathrm{km}$-scale irregularities that produce interference patterns on the ground and cause UHF scintillations. Furthermore, the $\mathrm{km}$-scale ionospheric irregularities are assumed to drift both horizontally and vertically with the ambient plasma (frozenin condition), the same drift that is seen by incoherent scatter radars. The characteristics of the zonal drift model presented here are well established and generally agree with the statistics of published radar data.

The results for vertical drifts from UHF measurements are encouraging, but tentative, and several questions remain. First, there is the applicability of the simple geometry used here, which should be compared with a full treatment of slant propagation through a real ionosphere. For low elevation angles, however, the approximations in propagation models like Costa and Basu (2002) and similar studies probably would not be valid. Second, Bhattacharyya et al. (2001) noted that 
Table 1. Model coefficients for equation A2

\begin{tabular}{rrrrrrrrrr}
\hline \multicolumn{10}{c}{$K_{p}{ }^{*}$} \\
\hline LT & $\mathrm{C}_{1}$ & $\mathrm{C}_{2}$ & $\mathrm{C}_{3}$ & $\mathrm{C}_{4}$ & $\mathrm{C}_{5}$ & $\mathrm{C}_{6}$ & XBAR & YBAR & SS \\
\hline 19:00-20:00 & 85.18 & 1.00 & -5.15 & -1.26 & -1.32 & -25.00 & 213.78 & 23.94 & 40.29 \\
20:00-21:00 & 125.08 & 2.40 & -19.74 & 0.12 & 0.55 & -18.71 & 203.05 & 21.86 & 41.93 \\
21:00-22:00 & 130.41 & 1.84 & -23.81 & 1.68 & 0.28 & -21.44 & 194.61 & 20.99 & 42.78 \\
22:00-23:00 & 126.47 & 0.13 & -23.57 & 0.20 & 1.71 & -10.54 & 193.75 & 21.23 & 44.14 \\
23:00-00:00 & 109.54 & 0.15 & -24.09 & -0.22 & 0.61 & -19.15 & 193.25 & 21.03 & 43.63 \\
00:00-01:00 & 82.34 & 1.10 & -22.87 & 1.19 & -0.15 & -31.31 & 190.26 & 21.18 & 43.97 \\
01:00-02:00 & 59.63 & 1.54 & -27.13 & 2.25 & 1.81 & -27.18 & 187.58 & 20.02 & 42.99 \\
02:00-03:00 & 52.03 & 1.37 & -29.78 & 2.27 & 4.06 & -39.97 & 189.75 & 21.17 & 44.41 \\
03:00-04:00 & 48.94 & 0.97 & -28.19 & 1.52 & 4.58 & -43.12 & 199.09 & 24.33 & 44.90 \\
04:00-05:00 & 48.60 & -2.31 & -32.67 & -0.92 & 2.02 & -23.31 & 205.09 & 25.86 & 39.44 \\
05:00-06:00 & 34.15 & -6.49 & -29.17 & -3.44 & 2.12 & -21.03 & 204.14 & 28.37 & 37.25 \\
06:00-07:00 & 0.66 & -4.34 & -28.12 & -3.33 & 1.56 & -19.43 & 210.80 & 30.45 & 38.01 \\
\hline
\end{tabular}

\begin{tabular}{rrrrrrrrrr}
\hline \multicolumn{10}{c}{ Solar Flux } \\
\hline LT & $\mathrm{C}_{1}$ & $\mathrm{C}_{2}$ & $\mathrm{C}_{3}$ & $\mathrm{C}_{4}$ & $\mathrm{C}_{5}$ & $\mathrm{C}_{6}$ & XBAR & YBAR & SS \\
\hline 19:00-20:00 & 92.72 & 0.77 & 23.28 & -4.27 & -2.99 & -11.74 & 213.78 & 119.51 & 67.91 \\
20:00-21:00 & 136.96 & 3.24 & 47.66 & -0.24 & 1.64 & -22.29 & 203.05 & 132.99 & 76.27 \\
21:00-22:00 & 142.76 & 1.21 & 43.37 & 3.76 & -0.07 & -16.90 & 194.61 & 138.25 & 79.85 \\
22:00-23:00 & 137.32 & -1.79 & 36.54 & -2.40 & -1.04 & -5.10 & 193.75 & 137.78 & 80.99 \\
23:00-24:00 & 118.36 & -1.81 & 35.47 & -4.06 & 1.15 & -0.24 & 193.25 & 136.35 & 81.44 \\
00:00-01:00 & 92.67 & -0.01 & 33.25 & 0.06 & 1.71 & -0.74 & 190.26 & 138.99 & 81.98 \\
01:00-02:00 & 70.76 & 1.77 & 30.09 & 3.93 & -0.94 & -1.09 & 187.58 & 144.99 & 82.90 \\
02:00-03:00 & 64.78 & 1.96 & 26.66 & 3.82 & -2.39 & -4.50 & 189.75 & 150.70 & 83.70 \\
03:00-04:00 & 64.40 & -1.03 & 26.49 & 0.14 & 0.15 & -4.05 & 199.09 & 147.60 & 81.91 \\
04:00-05:00 & 60.15 & -7.42 & 23.00 & -6.58 & 1.42 & -1.59 & 205.09 & 141.71 & 75.73 \\
05:00-06:00 & 44.12 & -14.05 & 17.84 & -13.92 & 0.71 & -0.43 & 204.14 & 133.40 & 68.85 \\
06:00-07:00 & 10.83 & -8.78 & 7.16 & -10.90 & 2.94 & -4.76 & 210.80 & 135.80 & 66.02 \\
\hline
\end{tabular}

spaced antenna drift velocities might not reflect the ambient plasma drift during the turbulent early stage of plasma bubble development, which typically occurs before 22:00 LT. In fact, the top panels of Figs. 9a-e show that the drift measured by Ancon-E fluctuates considerably more than the zonal drift at Antofagasta at all local times, which indicates that the vertical motion of the irregularities is generally more variable than the zonal drift. The variability, as seen in the lower panels of Figs. 8a-e, is similar to the Julia data at most times. Finally, the horizontal velocities used in the calculations are not at the Ancon-E ionospheric intersection point, but either at a higher altitude, when coming from the Antofagasta data, or at a different longitude, when coming from the Ancon-W data.

\section{Appendix A}

The model drift at Ancon for a desired solar flux and $K_{p} *$ is given by

$$
\begin{aligned}
\mathrm{V}_{\text {model }} & =\mathrm{V}_{\text {fit }}(\text { solar flux }) \\
& +\left(\mathrm{V}_{\text {fit }}\left(K_{p} *\right)-\mathrm{V}_{\text {fit }}\left(K_{p} *=20\right)\right),
\end{aligned}
$$

where $K_{p} *=10 K_{p}$ and $K_{p}=0 ., 0.33,0.67,1.00, \ldots$ Each velocity term, $\mathrm{V}_{\text {fit }}$, is expressed in terms of the row of coefficients for a local time in the appropriate table.

$\mathrm{V}_{\mathrm{fit}}=\mathrm{C}_{1}+\mathrm{C}_{2} \mathrm{X}+\mathrm{C}_{3} \mathrm{Y}+\mathrm{C}_{4} \mathrm{X}^{2}+\mathrm{C}_{5} \mathrm{XY}+\mathrm{C}_{6} \mathrm{Y}^{2}$

$\mathrm{X}=(\mathrm{DOY}-\mathrm{XBAR}) / \mathrm{SS}$, where DOY $=$ day of year $(1-365)$. $\mathrm{Y}=(\mathrm{GPH}-\mathrm{YBAR}) / \mathrm{SS}$, where $\mathrm{GPH}=$ geophysical parameter (solar flux or $K_{p}{ }^{*}$ ).

Acknowledgements. We thank J. Espinoza and R. Villafani for their dedication to the smooth operation of the spaced receiver scintillation instrument at Ancon, Peru. This material is based upon work supported by the NSF under Grants 0123560 and 0243294. The work at Boston College was also partially supported by Air Force Research Laboratory contract F19628-02-C-0087, AFOSR task 2311AS. The observatory at Ancon is operated by the Geophysical Institute of Peru, Ministry of Education. The Jicamarca Radio Observatory is operated by the Geophysical Institute of Peru, Ministry of Education, with support from the National Science Foundation Cooperative Agreement ATM-9911209 through Cornell University.

Topical Editor M. Lester thanks W. R. Coley and another referee for their help in evaluating this paper. 


\section{References}

Basu, S., Kudeki, E., Basu, S., Valladares, C. E., Weber, E. J., Zengingonul, H. P., Bhattacharyya, S., Sheehan, R., Meriwether, J. W., Biondi, M. A., Kuenzler, H., and Espinoza, J.: Scintillations, plasma drifts, and neutral winds in the equatorial ionosphere after sunset, J. Geophys. Res., 101, 26 795-26 809, 1996.

Bhattacharyya, A., Basu, S., Groves, K. M., Valladares, C. E., and Sheehan, R.: Dynamics of equatorial F-region irregularities from spaced receiver scintillation observations, Geophys. Res. Lett., 28, 119-122, 2001.

Coley, W. R. and Heelis, R. A.: Low-latitude zonal and vertical ion drifts seen by DE 2, J. Geophys. Res., 6751, 1989.

Costa, E. and Basu, S.: A radio wave scattering algorithm and irregularity model for scintillation predictions, Radio Sci., 37, 10.1029, 2002.

Eccles, J. V.: A simple model of low latitude electric fields, J. Geophys. Res., 103, 26 699-26 708, 1998.

Fejer, B. G., de Paula, E. R., Gonzalez, S. A., and Woodman, R. R.: Average vertical and zonal F-region plasma drifts over Jicamarca, J. Geophys. Res., 96, 13 901, 1991.

Fejer, B. G., Farley, D. T., Gonzales, C. A., Woodman, R. F., and Calderon, C.: F-region east-west drifts at Jicamarca, J. Geophys. Res., 86, 215, 1981.

Fejer, B. G., Kudeki, E., and Farley, D. T.: Equatorial F-region zonal plasma drifts, J. Geophys. Res., 90, 12 249-12 255, 1985.

Fejer, B. G. and Scherliess, L.: Empirical models of storm time equatorial zonal electric fields, J. Geophys. Res., 102, 24047 24 056, 1997.

Fejer, B. G. and Scherliess, L.: Mid- and low latitude promptpenetration ionospheric zonal plasma drifts, Geophys. Res. Lett., 25, 3071, 1998 .
Fejer, B. G., Scherliess, L., and de Paula, E. R.: Effects of the vertical plasma drift velocity on the generation and evolution of equatorial spread F, J. Geophys. Res., 104, 19 859-19869, 1999.

Kil, H., Kintner, P. M., de Paula, E. R., and Kantor, I. J.: Global positioning system measurements of the ionospheric zonal apparent velocity at Cachoeira Paulista in Brazil, J. Geophys. Res., 105, 5317-5327, 2000.

Pingree, J. E. and Fejer, B. G.: On the height variation of the equatorial F-region vertical plasma drifts, J. Geophys. Res., 92, 4763, 1987.

Rishbeth, H.: Polarization fields produced by winds in the equatorial F-region, Planet Space Sci., 19, 357-369, 1971.

Rishbeth, H.: The F-region dynamo, J. Atmos. Terr. Phys., 43, $387-$ 392, 1981.

Scherliess, L. and Fejer, B. G.: Radar and satellite global equatorial F-region vertical drift model, J. Geophys. Res., 104, 6829-6842, 1999.

Vacchione, J. D., Franke, S. J., and Yeh, K. C.: A new analysis technique for estimating zonal irregularity drifts and variability in the equatorial F-region using spaced receiver scintillation data, Radio Sci., 22, 745, 1987.

Valladares, C. E., Meriwether, J. W., Sheehan, R., and Biondi, M. A.: Correlative study of neutral winds and scintillation drifts measured near the magnetic equator, J. Geophys. Res., 107, A7, 10.1029, 2002.

Valladares, C. E., Sheehan, R., Basu, S., Kuenzler, H., and Espinoza, J.: The multi-instrumented studies of equatorial thermosphere aeronomy scintillation system: Climatology of zonal drifts, J. Geophys. Res., 101, 26 939, 1996. 